\title{
Information and Knowledge Flows in the Network of the Education through Work for Family Health Program
}

\author{
Ana Áurea Alécio de Oliveira Rodrigues ${ }^{1,2}$, Claudia Ribeiro Santos Lopes ${ }^{2,3}$, Eliane Santos Souza ${ }^{2,4}$, \\ Inácio de Sousa Fadigass ${ }^{1}$, Hernane Borges de Barros Pereira ${ }^{2,5,6}$ \\ ${ }^{1}$ Universidade Estadual de Feira de Santana, Feira de Santana, Brazil \\ ${ }^{2}$ Programa de Difusão do Conhecimento, DMMDC/UFBA, Salvador, Brazil \\ ${ }^{3}$ Universidade Estadual do Sudoeste da Bahia, Jequié, Brazil \\ ${ }^{4}$ Universidade Federal da Bahia, Salvador, Brazil \\ ${ }^{5}$ Universidade do Estado da Bahia, Salvador, Brazil \\ ${ }^{6}$ Programa de Modelagem Computacional, SENAI Cimatec, Salvador, Brazil \\ Email: aaaorodrigues@gmail.com, clopesuesb@gmail.com, isfadigas@gmail.com, hbbpereira@gmail.com, elianesouza@ufba.br
}

Received December 23, 2013; revised January 26, 2014; accepted February 17, 2014

Copyright (c) 2014 Ana Áurea Alécio de Oliveira Rodrigues et al. This is an open access article distributed under the Creative Commons Attribution License, which permits unrestricted use, distribution, and reproduction in any medium, provided the original work is properly cited. In accordance of the Creative Commons Attribution License all Copyrights (C) 2014 are reserved for SCIRP and the owner of the intellectual property Ana Áurea Alécio de Oliveira Rodrigues et al. All Copyright (C 2014 are guarded by law and by SCIRP as a guardian.

\section{ABSTRACT}

The Education through Work for Family Health Program (PET Saúde, in Portuguese) created by the Ministries of Education and Health is a proposal to integrate service, learning and community. The goal of PET Saúde is to foster the formation of learning groups within the Family Health Strategy scope. While being studied at the city of Feira de Santana, the program was structured with one coordinator and eleven tutorial groups, distributed in 27 family health offices, which constituted a social network where the construction and knowledge diffusion occur. This article proposes the analysis of the information and knowledge flows of this network through the social networks analysis. This study highlights the play of PET Saúde's coordinator in the processes of organization and articulation as central vertex of the network, and some scholars in the articulation of different tutorial groups. The results show a fragmentation in the PET Saúde network when the coordinator vertex is removed, whereas 5 components are generated where 4 tutorial groups appear isolated.

\section{KEYWORDS}

Social Networks; Education-Service Interaction; Health; Information; Knowledge

\section{Introduction}

The Education through Work for Family Health Program (PET Saúde, in Portuguese) is one of the intersectional actions aimed to the integration conduction of service, learning and community, basic axis to the reorientation of education in the health area. The program started in 2009 through a partnership between the Secretariat of Work Management (SGTES), the Secretariat of Health Care (SAS) of the Ministry of Health and the Secretariat of Higher Education (SESU) of the Ministry of Education [1]. It is characterized as one of the actions of the Professional Education Reorientation in Health National Program (Pró-Saúde), which was created in 2005. Pró-
Saúde has its perspective on connecting the graduation process with the necessity of Basic Attention, which are essentially translated in Brazil into Family Health Strategy (ESF) [2].

The general goal of PET Saúde is to foster the formation of tutorial learning groups within the ESF by designating an instrument for the service qualification of health professionals and for the work initiation and experience. The program is directed to the health undergraduate students, according to the Public Health System (SUS) needs, and in the perspective of the service insertion as source of knowledge and research production at the educational institutions [3].

PET Saúde is used to enable improvement and specia- 
lization programs for health professionals, and also to initiate the students into the health service practice. This program carries the key concept of reorientation in the health education. After each activity executed, each actor has its attributions defined.

The "Coordinator" must follow up all the developed activities in the Program by orienting the tutors and preceptors actions with the student and scholar teams, connecting the local PET Saúde and the State and Municipal Secretariats, and providing the National Program Coordination with semi-annual reports about the work developed by the tutorial groups.

The "Tutor" has a teaching-care supervision function in field and its role is directed to the health professionals linked to the university. These professionals carry the role of reference leader to the health area professionals and/or health students. Therefore, the requirements for the academic tutor are planning and leading bimonthly meetings for the tutorial groups, promoting meetings with the preceptors team for activity evaluation and planning, orienting monitors to the planning and development of education, research and scope activities, maintaining the group interaction through digital technology, supervising the activities developed by the monitors/preceptors in the Health Services, stimulating and supporting the participation of monitors and preceptors in technical-scientific events, attending the Clinical Excellence Centre Applied in Basic Attention meetings and the events promoted by the Program, evaluating the Monitors' Monthly Frequency File, in addition to other administrative attributions.

The "Preceptor" must orient the monitors to the planning and development of the teaching, researching and scope activities at the respective health offices. Also, the preceptor must orient the monitors in the Tutorial Group Biannual Report elaboration, so it can be sent to the respective tutor. Finally, the preceptor must participate with the students in the scientific work elaboration, publication and/or presentation. Each preceptor will be responsible for the learning in service of 02 (two) health graduating students with scholarship and 01 (one) volunteer student.

The PET Saúde's student monitoring is referred to the development of service experiences and research activities under orientation of the preceptor and tutor. It aims at the production and dissemination of relevant knowledge in the health area and the work initiation activities.

The "Scholar" and "Volunteer" must publish or present academic reports in the event of scientific nature, in which they must broach activities or researches done during their participation in the Program. The monitor may execute individual care actions in his/her graduation area and under the preceptor direct supervision.

PET Saúde at State University of Feira de Santa-
na/Municipal Health Office (UEFS/SMS) was implanted in Feira de Santana, municipality of State of Bahia, in April 2009 through 23 Family Health Offices (USF), and it was structured in tutorial groups. Each tutorial group holds 01 tutor, 06 preceptors and 30 students (scholars and volunteers). Today, this group is formed by 11 tutors, 66 preceptors and 132 scholars and volunteers, distributed in 27 Family Health Offices (USF).

In 2010, the Ministries of Health and Education changed the title PET Saúde to PET Saúde da Família (in English, PET Family Health). In January 2011, they authorized the formation of one more team for UEFS's PET Saúde, which then hold 11 tutorial groups [4].

The objective of this article is to analyze the information and knowledge flow which occur in this network and discuss the roles taken by the different actors working for PET Saúde, aiming to indentify the actors with more influence in the network. In this work, we take into account as the most influential vertex, one that provides more interaction between network members [5].

\section{Social Network Analysis}

The concept of Social Network is related to a group of social actors (people, organizations, companies or social entities) that is connected through relationships originated by feelings, information/communication, professional relationship, etc. In a social network, these actors are called vertices or nodes. The relations between the vertices are identified as edges or arcs, in case of a directed network [6,7].

By analyzing the social network it is possible to identify patterns of performances, cooperation and information flow between people, groups and/or organizations in a given society. These elements are important indicators that can contribute to evaluation and strategic planning actions in both public and private sphere to support the management [8].

According to $[9,10]$, a social network can be analyzed through degree, closeness and betweenness centrality measurements.

The Degree Centrality is related to the number of ties (connections or edges) an actor holds with other actors in the network, indicating the local centrality of the vertex $[9,10]$. Consequently, the most centered vertex in the network is the one with the highest degree, in other words, a greater number of connections which are adjacent with other actors in the same network.

In the studied PET Saúde network, the local centrality of the vertex indicates the number of other actors being searched by "Scholars" or "Volunteers" in order to get information to clear doubts and/or problems faced every day. The higher the degree centrality is, the greater the communication flow occurring between this actor and the 
other network actors will be.

The Closeness Centrality, however, is based on the distance between vertices and it focus on how close an actor is, compared with the other network actors. It is safe to assert that the closeness centrality is conversely related to the distance between the vertices of a network $[9,10]$. Consequently, the smaller the distance between a vertex and the rest of the network is, the higher its closeness centrality. In the case of PET Saúde Network, this index indicates with which network actors a vertex (Scholar or Volunteer) has smaller distance when searching for information.

With the Betweenness Centrality it is possible to evaluate the interactions between two non-adjacent vertices at the vertices located in the path between them $[9,10]$. Thus, a vertex has high betweenness centrality when it is through the path between many others. In the PET Saúde Network, this centrality indicates the vertex influence at the information and knowledge flow related to the other components forming the network.

By analyzing a network, it is safe to use other indices, such as average degree, diameter, average clustering coefficient, average shortest path, etc. Towards these indices, it is possible to cognize the topology of the analyzed network and to obtain a general view of its structure.

\section{Analysis Method}

The theory of the social network was the chosen method for the analysis of the broached data. The Gephi-0.8.1 version and the MS Excel spreadsheet programs were respectively used for index calculation, network views and data tabulation.

The studied network is formed by the PET Saúde tutorial groups, in which actors are designated according to their role in the Program and titled as Coordinator, Tutor, Preceptor, Scholar and Volunteer.

Aiming the information and knowledge flow analysis in the network, as well as the identification of the actors with greatest influence and power, a network was created towards the data collection performed in July 2011. The network was built by means e-mails sent us to 132 scholars and 16 volunteers member of the PET Saúde. This way, in order of preference, they would indicate which of the network members among them searched for problem solution information inside the unit of operation or even for doubt clearing about a procedure, conduct or developed activity in the Program.

One hundred and three scholars and 11 volunteers responded to the email survey. The studied PET Saúde network is a directed network formed by 173 vertices (actors inside the network-tutor, professional, scholar or volunteer) and 281 arcs (connections between the vertices). Information and knowledge flows in studied net- work are promoted by the arcs that connect vertices "scholar" and "volunteer".

The network was analyzed on the basis of its properties characterized by: number of vertices $(V)$; number of arcs $(E)$; average degree $(<k>)$; diameter $(D)$; average clustering coefficient $(C)$; average shortest path $(L)$; amount of components.

Considering the knowledge and information flow, the actors' performance in the network was evaluated on the basis of the metrics of the degree centrality $(D C)$, the closeness centrality $(C C)$, the betweenness centrality $(B C)$ and the vertex clustering coefficient $\left(C C^{1}\right)$. This coefficient can be defined as the relation between the number of existing edges between the vertices adjacent to the analyzed one and the maximum number of possible edges between these ones. This way, the clustering coefficient indicates how connected the neighborhoods of a vertex are connected [11].

The in-degree $\left(G_{e}\right)$ and out-degree $\left(G_{s}\right)$ of each vertex were also observed as to identify the most searched actors by the students to get pieces of information. The in-degree of a vertex indicates the number of times the vertex was mentioned; the out-degree, the number of other network vertices mentioned by it.

The experiments were performed in two distinct scenarios. First (Scenario 1), the network was analyzed as a whole (Network 01), based on the received replies. The result was a general view of the PET Saúde network communication flow. Then, a new network based on the Network 01 was generated for analysis. However, the "Coordinator" (Scenario 2) vertex was eliminated for the verification of importance and performance of the "Tutor" and "Professional" actors inside the network.

The complete network (Scenario 1) is formed by 173 vertices and 281 arcs (Figure 1). The second network generated by eliminating the "Coordinator" vertex (Scenario 2) has 172 vertices and 235 arcs, in five components. This network is presented in the Figures 2 and 3 .

As the second network presented 5 components in the Scenario 2, new experiments were performed with the largest component (i.e. subgraph with the largest number of vertices), which represents $70 \%$ of the whole network (not eliminating the vertex "Coordinator"). In Figure 1, it is possible to observe how the information flow can occur in the whole PET Saúde Network.

In the Figures 1 and 2, the information and knowledge flow between students and other PET Saúde members is observed.

\section{Result Analysis}

According to the Figure 1 and Table 1, it is possible to observe that the studied PET Saúde Network is a completely connected network when analyzed in Scenario 1, where all the network vertices are found. Also, it holds 


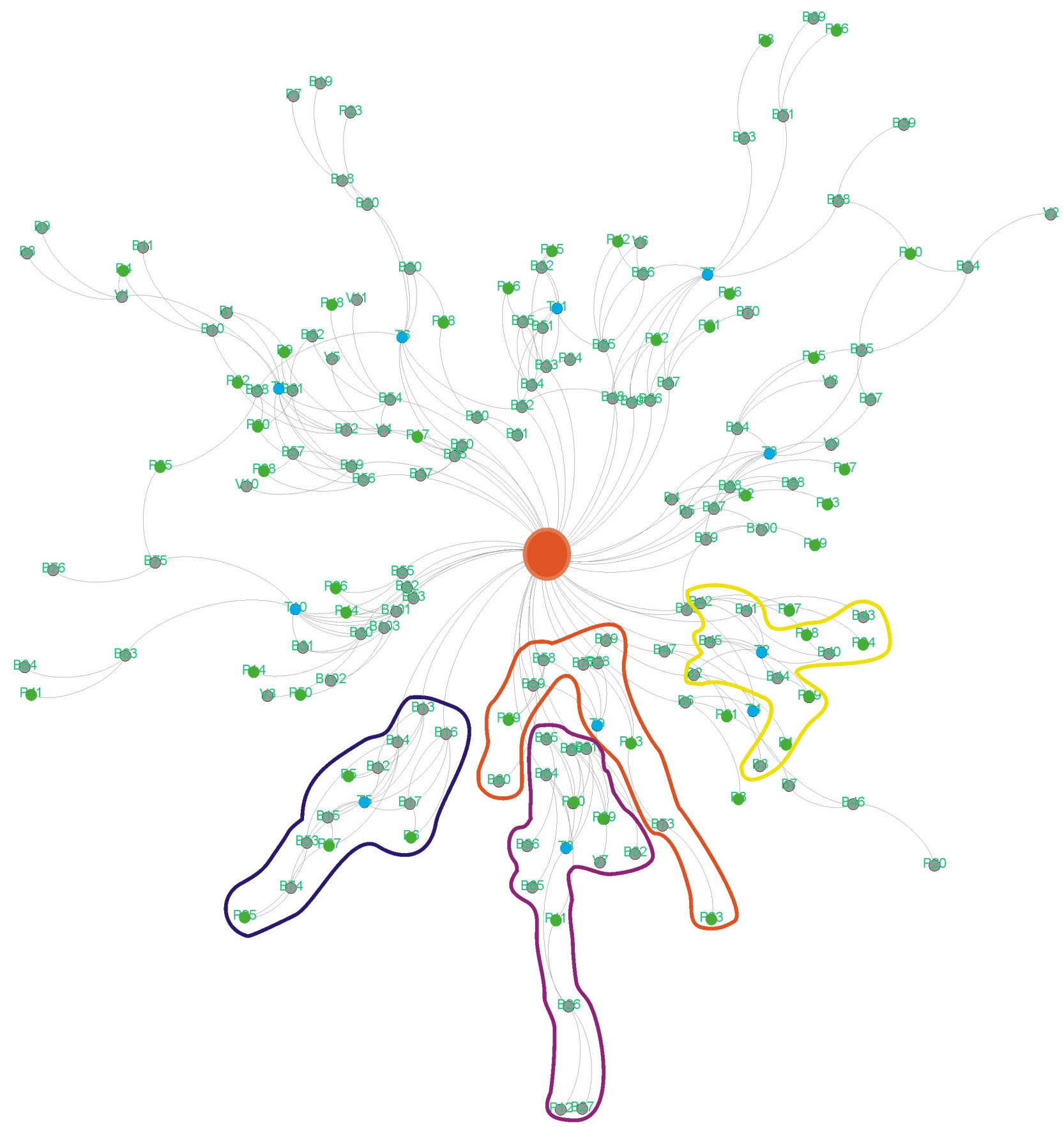

The central vertex "Coordinator"

Figure 1. Network with all the vertices (Scenario 1), highlighting the “Coordinator" vertex, which presented the highest Degree Centrality (network central vertex). Four subgroups of vertexes are shown in the figure and consist of components (shown separately in Figure 3) which emerged after removal of the vertex "Coordinator". The remaining vertices belong of the largest component, shown in Figure 2.

single component, and average degree of connections between the vertices of 1.62 . However, when the central "Coordinator" vertex is removed, the network is no longer completely connected so it gets divided into 5 components (Figures 2 and 3), yet with no significant modification by the other network. This suggests that the network communication flow is more intense at the largest component, what justifies the performance of experiments with this component to complement our analysis. The PET Saúde network properties are presented in 


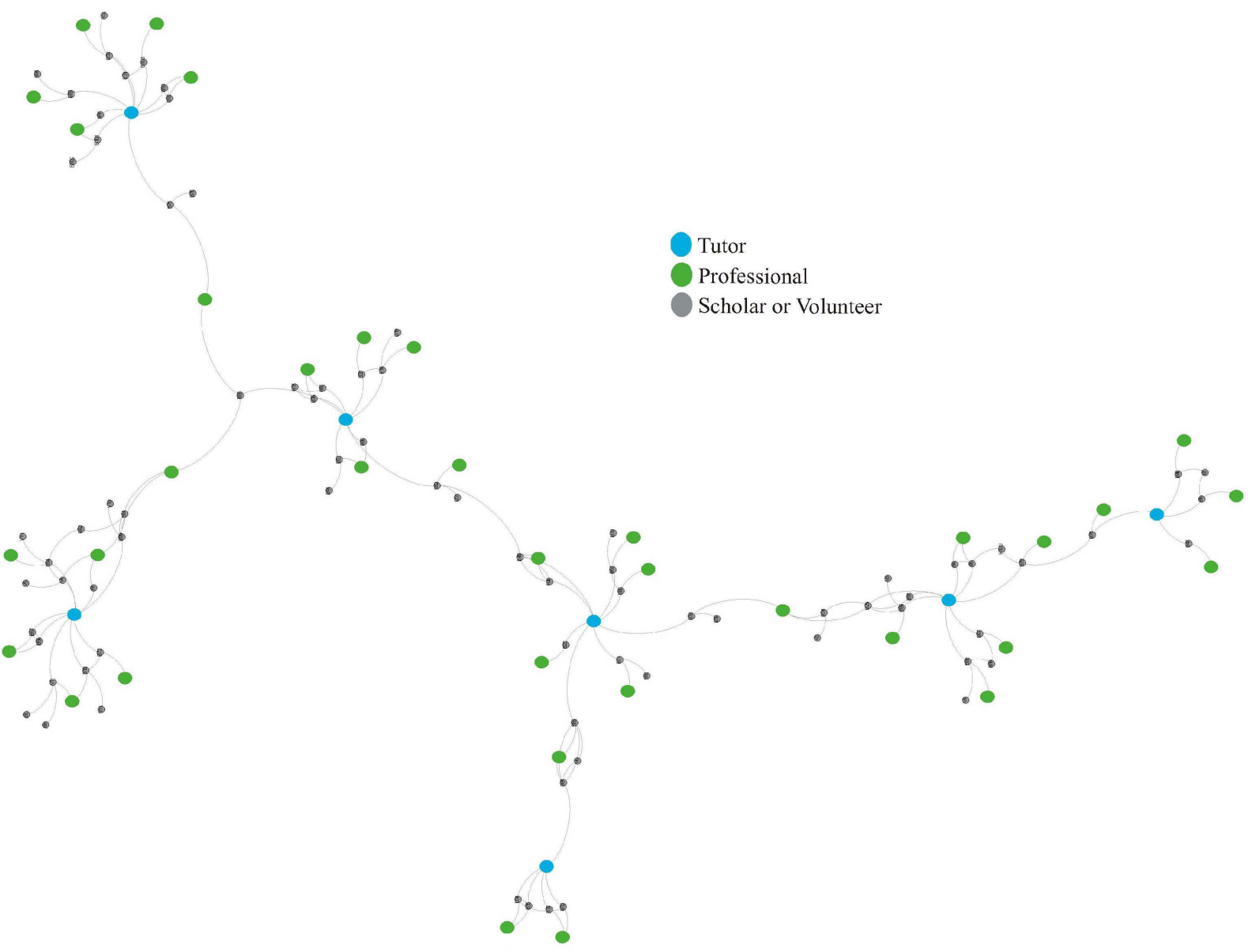

Figure 2. Largest component network (Scenario 2), composed of $70 \%$ of the vertices related to the whole network.
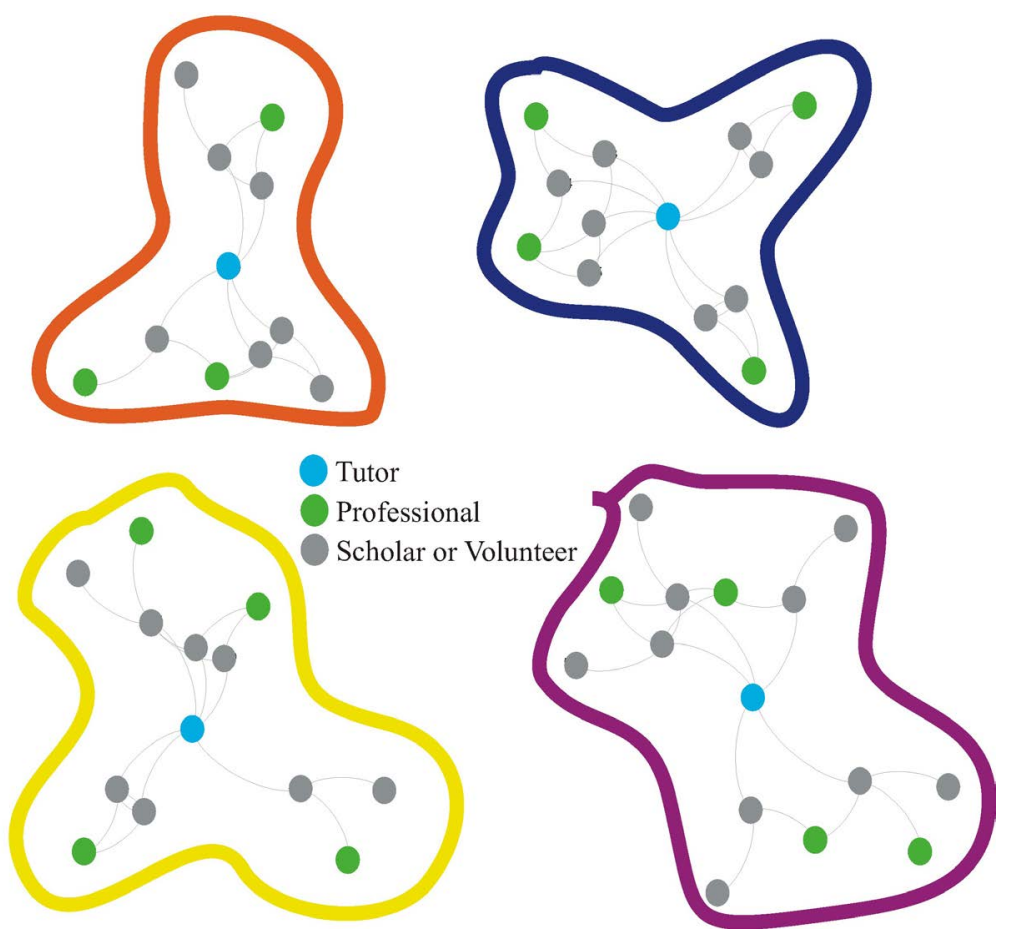

Figure 3. Other components of the network when the "Coordinator" vertex is removed (Scenario 2). 
Table 1. Compiled properties of the networks generated from PET Saúde for the information and knowledge flow analysis.

\begin{tabular}{cccccccc}
\hline Network & $\boldsymbol{V}$ & $\boldsymbol{E}$ & $<\boldsymbol{k}>$ & $\boldsymbol{D}$ & $\boldsymbol{C}$ & $\boldsymbol{L}$ & Qt. Comp. \\
\hline Scenario1 & 173 & 281 & 1.62 & 3 & 0.12 & 1.14 & 1 \\
Scenario2 & 172 & 235 & 1.36 & 3 & 0.13 & 1.14 & 5 \\
Largest component & 120 & 160 & 1.33 & 3 & 0.12 & 1.16 & 1 \\
\hline
\end{tabular}

Table 1, including the largest component (Scenario 2).

The results from Scenario 1 present a strong concentration of information at the person of the vertex holding the coordinator role in the PET Saúde group. This power concentration in a single vertex may designate certain "fragility" in the network, once in case the coordinator is removed from the network topologic structure, it can suffer an information flow discontinuity. Still, this concentration is seen as natural due to the management model defined to the program, where the Coordinator of the Tutorial Groups represents a mediating role among the other network members.

Nevertheless, it stands out that even though the Coordinator has been the most noticed vertex by the students, it was not named as first preference, but often as last.

When analyzing the complete network, the coordinator presents the greatest value of degree centrality, and this refers to the vertex with greatest influence for the information flow in the network as a whole. In this context, it is observed that the information transits faster between the actors due to the position assumed by the coordinator.

It is important to highlight that the indices of closeness and betweenness centrality were not considered in the analysis of the "Coordinator" vertex position because the network was formed after a research performed among the PET Saúde member students only, and dealing with a directed network, in this case, the indices of closeness and betweenness centrality was 0 .

Towards these results, the analysis of the second scenario became interesting for the information flow observation between scholars and volunteers and the other network members, Tutors and Professionals. For being closer to the students, theoretically, both the Tutors and Health Professionals of the PET Saúde network should have a leading role in the professional formation, this way actively working for the information flow requested by the students. However, the results reflect that the practice diverges from the theory, and essentially concerning the "Professional" actor, holder of preceptor role in the network, it does not present the expected influence in the network communication and information flow. To clarify the articulation and role of the diverse actors in the group, experiments with Scenario 2 were performed.

Aiming the analysis of the network position in Scenario 2, only the largest component was considered. It was formed by $70 \%$ of the vertices (Figure 2); from which 07 tutorial groups form the network. With the creation of Scenario 2, it was possible to analyze the relation between the students and the other network members closely.

While calculating for the Network with the largest component, the importance of the Tutors in the group articulation was verified, through the values corresponding to the degree centralities and clustering coefficient, respectively, 9 and 0.1 .

Regarding the Professionals acting as preceptors in the Program and heading the students' graduation, however, degree centralities were lower than the ones presented by the Tutors, and the most emphasized vertices presented its degree centrality equaling 3 , yet with no change of clustering coefficient 0.1 .

The results show that it is possible to observe that even though the Professionals and Tutors present the same distance between the vertices, the Tutors have the greatest number of adjacent connections as they are more mentioned.

Still referring to the results of the largest component network, another important data to be considered is the fact that indices of degree (5.0), closeness (1.0) and betweenness centrality (4.0 and 3.0) were found "high" at the actors (vertices) holding the role of Scholars in the PET Saúde network, emphasizing the vertices B35, B54, B25, B48, B85 and B86. This means the Network Scholars hold a "certain influence" to the information flow among its pairs.

In Table 2, details of the centrality indices, clustering coefficient, in-degree and out-degree of the actors that integrate the largest component in PET Saúde network and the most emphasized actors are found.

Another interesting characteristic, and the best example of how the work should be done in the PET Saúde network, was represented by some "Scholar" vertices. They search for information among actors inside a tutorial group that is different from their acting group, turning network integration possible.

Consequently, the vertices B86, B48, B49, B61, B99, B79, B38, B68, B83, B24 and B78 are emphasized. In Table 3, the results obtained with these vertices are presented.

In Table 2, it is observed that all the values corresponding to the Closeness and Betweenness Centralities of the "Tutor" and "Professional" vertices, as occurred with the "Coordinator" vertex, equaled 0 . This happens because the data collection was only considered between "Scholars" and "Volunteers" integrating the network.

\section{Final Considerations}

Through the results and the subsequent analysis, it is 
Table 2. Indices presented by the remarkable actors in the PET Saúde network-largest component (in-degree- $-D_{i}$ and out-degree- $-D_{o}$, Degree, Closeness and Betweenness Centralities-DC, $C C$ and $B C$, Clustering Coefficient $-C C^{1}$ ).

\begin{tabular}{cccccccc}
\hline Actor & Vertex & $\boldsymbol{D}_{\boldsymbol{i}}$ & $\boldsymbol{D}_{\boldsymbol{o}}$ & $\boldsymbol{D C}$ & $\boldsymbol{C C}$ & $\boldsymbol{B C}$ & $\boldsymbol{C} C^{1}$ \\
\hline \multirow{5}{*}{ Tutor } & T1 & 9 & - & 9 & 0 & 0 & 0.05 \\
& T10 & 9 & - & 9 & 0 & 0 & 0.05 \\
& T3 & 8 & - & 8 & 0 & 0 & 0.05 \\
& T6 & 8 & - & 8 & 0 & 0 & 0.01 \\
& T7 & 8 & - & 8 & 0 & 0 & 0.05 \\
& P10 & 3 & - & 3 & 0 & 0 & 0.16 \\
& P9 & 3 & - & 3 & 0 & 0 & 0 \\
& P30 & 3 & 0 & 3 & - & - & 0.16 \\
& B25 & 3 & 2 & 5 & 1.0 & 3.0 & 0.15 \\
& B35 & 2 & 3 & 5 & 1.0 & 4.0 & 0.25 \\
& B48 & 2 & 3 & 5 & 1.0 & 3.0 & 0.16 \\
& B54 & 1 & 4 & 5 & 1.0 & 3.0 & 0.05 \\
& B85 & 1 & 4 & 5 & 1.2 & 1 & 0.16 \\
& B86 & 1 & 4 & 5 & 1.2 & 1 & 0.16 \\
\hline \multirow{5}{*}{} & & & & & &
\end{tabular}

Table 3. The indices were presented by the vertices that searched for information in tutorial groups that were different from the ones inside the PET Saúde network (largest component).

\begin{tabular}{ccccccc}
\hline Vertex & $\boldsymbol{D}_{\boldsymbol{i}}$ & $\boldsymbol{D}_{\boldsymbol{o}}$ & $\boldsymbol{D C}$ & $\boldsymbol{C C}$ & $\boldsymbol{B C}$ & $\boldsymbol{C} \boldsymbol{C}^{1}$ \\
\hline B86 & 1 & 4 & 5 & 1.20 & 1.00 & 0.17 \\
B48 & 2 & 3 & 5 & 1.00 & 3.00 & 0.17 \\
B49 & 1 & 3 & 4 & 1.00 & 0 & 0.33 \\
B61 & 1 & 3 & 4 & 1.00 & 2.00 & 0.08 \\
B99 & 0 & 4 & 4 & 1.33 & 0 & 0.08 \\
B79 & 1 & 3 & 4 & 1.00 & 3.00 & 0 \\
B38 & 0 & 3 & 3 & 1.00 & 0.00 & 0 \\
B68 & 0 & 3 & 3 & 1.00 & 0.00 & 0 \\
B83 & 0 & 3 & 3 & 1.00 & 0.00 & 0 \\
B24 & 0 & 3 & 3 & 1.25 & 0.00 & 0.17 \\
B78 & 0 & 3 & 3 & 1.50 & 0.00 & 0 \\
\hline
\end{tabular}

considered that the PET Saúde Coordinator performs a central role in the information dissemination and network organization, with a high degree of influence. The coordinator role, besides legal, is strategic in the process of student formation and in the qualification of the professionals working for the health public network, as observed at the information and knowledge flows in the Education through Work for Family Health Program network. This influence of the vertex "Coordinator" is formally established. However, in a real network, the influence of a vertex (i.e. actor) is established by virtue of its position and the relationships between it and the other actors, as observed in this study.

It is important to register that all the Tutors, from the working 11 , were pointed out, along with some scholars and the Coordinator as mediators in the network, emphasizing the importance of the "Tutor" actor.

Network dependence is evident in these actors which have shared information among the rest of the group members and have contributed to the health actions realization and to the performance improvement of PET Saúde.

It draws attention that several preceptors were not mentioned in the students' answers, even though they were the first leaders for the student activities follow-up at the Health Services.

This way, the actors' necessity of performance improvement is emphasized, especially the professionals' (Preceptors) that, while working for the network can become a transformation instrument in the health service practices developed at the Family Health Strategy scope, at the process of consolidate the proposition of preparing health professionals and qualifying the basic attention through insertion of graduating students.

Towards the results obtained, it is concluded that the analysis towards the social network theory presents itself as one of the appropriate methods to the comprehension of the PET Saúde network's information and knowledge flow.

Finally, it is important to comment that this work is an ongoing research and initially it was published in the proceedings of the 1st Brazilian Workshop on Social Network Analysis and Mining [12].

\section{REFERENCES}

[1] Brazil, "Portaria Interministerial no. 1.802, de 26 de Agosto de 2008 que Institui Programa de Educação pelo Trabalho Para a Saúde-Pet-Saúde,” Interministerial Ordinance no. 1.802, Institutition of the Education through Work for Health Program-Pet Saúde, In Federal Government, Brasília, 2008.

[2] Brazil, "Programa Nacional de Reorientação da Formação Profissional em Saúde Pró-Saúde, Ministério da Saúde,” Professional Education Reorientation in Health National Program (Pró-Saúde), Health Ministry, Education Ministry, Federal Government, Brasília, 2005.

[3] Brazil, "Portaria Conjunta $n^{\circ}$ 03, de 30 de Janeiro de 2009. Homologa o Resultado do Processo de Seleção dos Projetos que se Candidataram ao Programa de Educação pelo Trabalho para a Saúde-Pet-Saúde,” Joint Ordinance no. 03, Endorsement of the Results of the Project Selection Process of the Pet-Saúde Program Candidates, Federal Government, Brasília, 2009. 
[4] Brazil, "Portaria Interministerial $n^{0} 2$, de 03 de Março de 2010. Institui o Programa de Educação Pelo Trabalho para a Saúde da Família-Pet-Saúde da Família,” Interministerial Ordinance no. 2, Institution of the Education through Work for Faily Health Program-Pet-Saúde da Família, Federal Government, Brasília, 2010.

[5] C. R. Sugahara and W. C. S. Vergueiro, "Redes Sociais: Um Olhar Sobre a Dinâmica da Informação na Rede (APL) Arranjo Produtivo Local Têxtil, de Americana,” Revista Interamericana de Bibliotecología, Vol. 34, No. 2, 2011, pp. 177-186.

[6] H. B. B. Pereira, I. S. Fadigas, V. Senna, et al., "Semantic Networks Based on Titles of Scientific Papers," Physica A: Statistical Mechanics and Its Applications, Vol. 390, No. 6, 2011, pp. 1192-1197. http://dx.doi.org/10.1016/j.physa.2010.12.001

[7] R. Albert and L. Barabasi, "Statistical Mechanics of Complex Networks," Reviews of Modern Physics, Vol. 74, No. 1, 2002, p. 47. http://dx.doi.org/10.1103/RevModPhys.74.47

[8] H. B. B. Pereira, M. C. Freitas and R. R. Sampaio, "Fluxos de Informações e Conhecimentos para Inovações no Arranjo Produtivo Local de Confecções em Salvador, Bahia,” Revista de Ciência da Informação, Vol. 8, No. 4, 2007.

[9] L. C. Freeman, "Centrality in Social Networks: Conceptual Clarification,” Social Networks, Vol. 1, 1978, pp. 215-239.

http://dx.doi.org/10.1016/0378-8733(78)90021-7

[10] S. Wasserman and K. Faust, "Social Network Analysis: Methods and Applications,” Cambridge University Press, Cambridge, 1994.

http://dx.doi.org/10.1017/CBO9780511815478

[11] D. J. Watts, "Small Worlds: The Dynamics of Networks between Order and Randomness,” Princeton University Press, Princeton, 1999.

[12] A. A. A. O. Rodrigues, C. R. S. Lopes, E. S. Souza, I. S. Fadigas and H. B. B. Pereira, "Information and Knowledge Flows in the Network of the Education through Work for Family Health Program," Proceedings of the Brazilian Workshop on Social Network Analysis and Mining, XXXII Congress of the Brazilian Computer Society Computer Society, Curitiba, 2012. 